\title{
HOW TO PREVENT PSYCHIATRIC INPATIENT READMISSIONS? A RETROSPECTIVE STUDY IN A PORTUGUESE PSYCHIATRIC UNIT
}

A.B. Medeiros, A. Carapucinha, T. Mendonça, A. Barcelos, C. Fernandes Santos, C. Miranda, F. Martins, M. Bernardo, N. Descalço,

P. Casimiro, V. Henriques, F. Gonçalves

Garcia de Orta Hospital, Psychiatry and Mental Health Department, Almada, Portugal

objectives and Background

Inpatient readmissions:

$\begin{gathered}\checkmark \text { Poor Prognosis } \\ \checkmark \text { Weak community } \\ \text { and ambulatory responses }\end{gathered}$
$\begin{gathered}\text { Quality parameter in } \\ \text { healthcare services } \\ \text { Rarticularly those occurring } \\ \text { during the first 30 days after } \\ \text { hospital discharge. }\end{gathered}$
In psychiatry, different aspects besides the strictly clinical ones
may increase the likelihood of readmission.
Aim:
To determine the predictive characteristics for readmission in a

Material and Methods

Patients admitted to psychiatry unit | Jan 2016 - Dec 2017

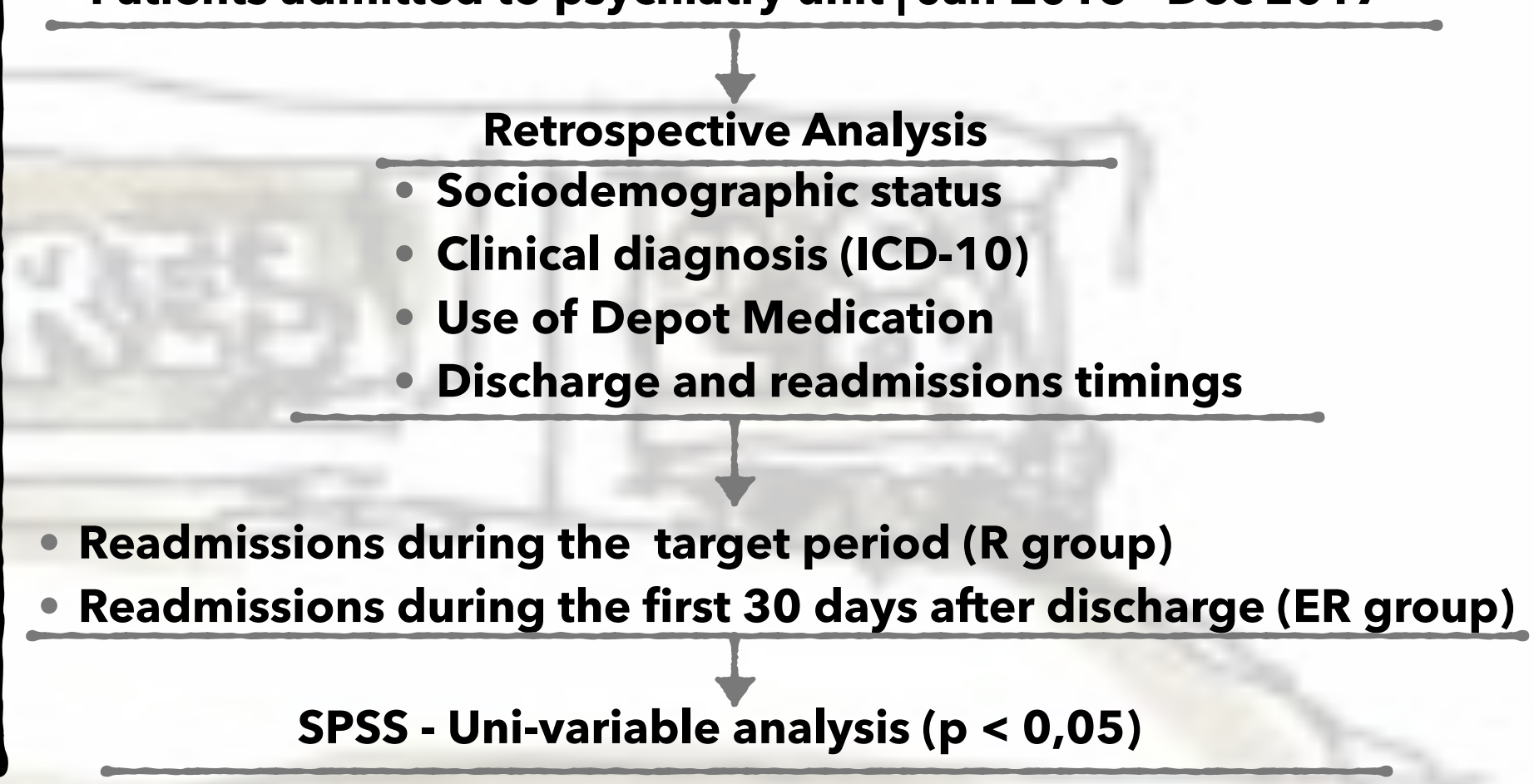

\section{Results and Conclusions}

\section{Total (T group)}

\section{- $\mathbf{N}=776$}

51.2\% males

79.4\% unemployed/retired

$75.5 \%$ unmarried

52.2\% under depot medication

PS: $21.9 \%$

BAP (M-with P): 7.3\%
Readmissions (R group)

- $\mathrm{N}=169$

- $57.4 \%$ males

83.4\% unemployed/retired

$-80.5 \%$ unmarried

Early Readmissions (ER group)
$\mathbf{N}=\mathbf{2 7}$
$\mathbf{6 4 . 5} \%$ males
$\mathbf{8 7 . 3 \%}$ unemployed/retired
$\mathbf{8 1 . 3 \%}$ unmarried
$\mathbf{4 8 . 2} \%$ under depot medication
PS: $\mathbf{3 7 . 6 \%}$
BAP (M-with P): $\mathbf{2 4 . 5 \%}$

$100 \%$

$\square$ T group

Rgroup

[ ER group

- BAP (M-with P): $24.5 \%$

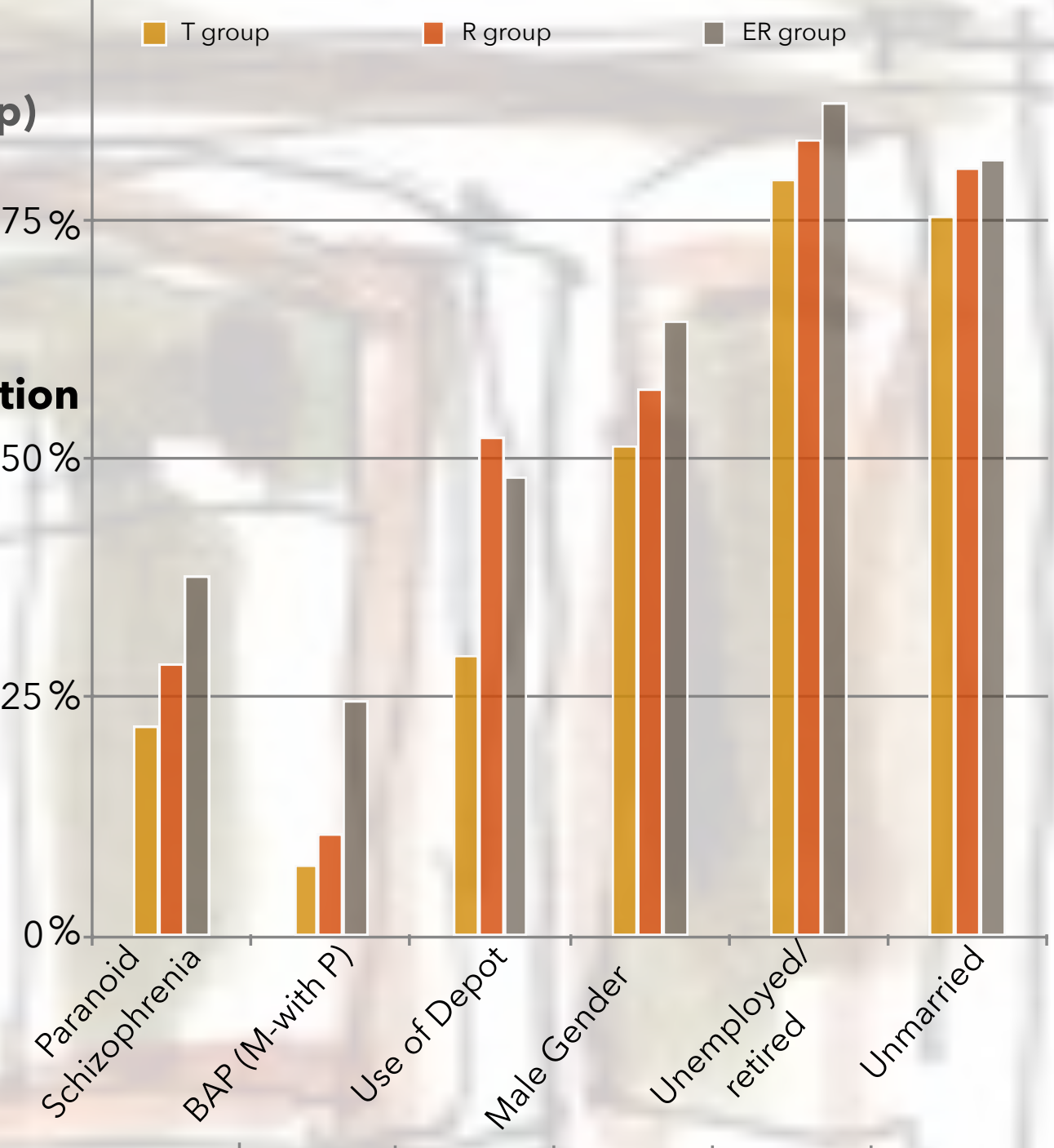

PS - Paranoid Schizophrenia BAP - Bipolar Affective Disorder $M$ with $\mathrm{P}$ - Mania with psychotic symptoms
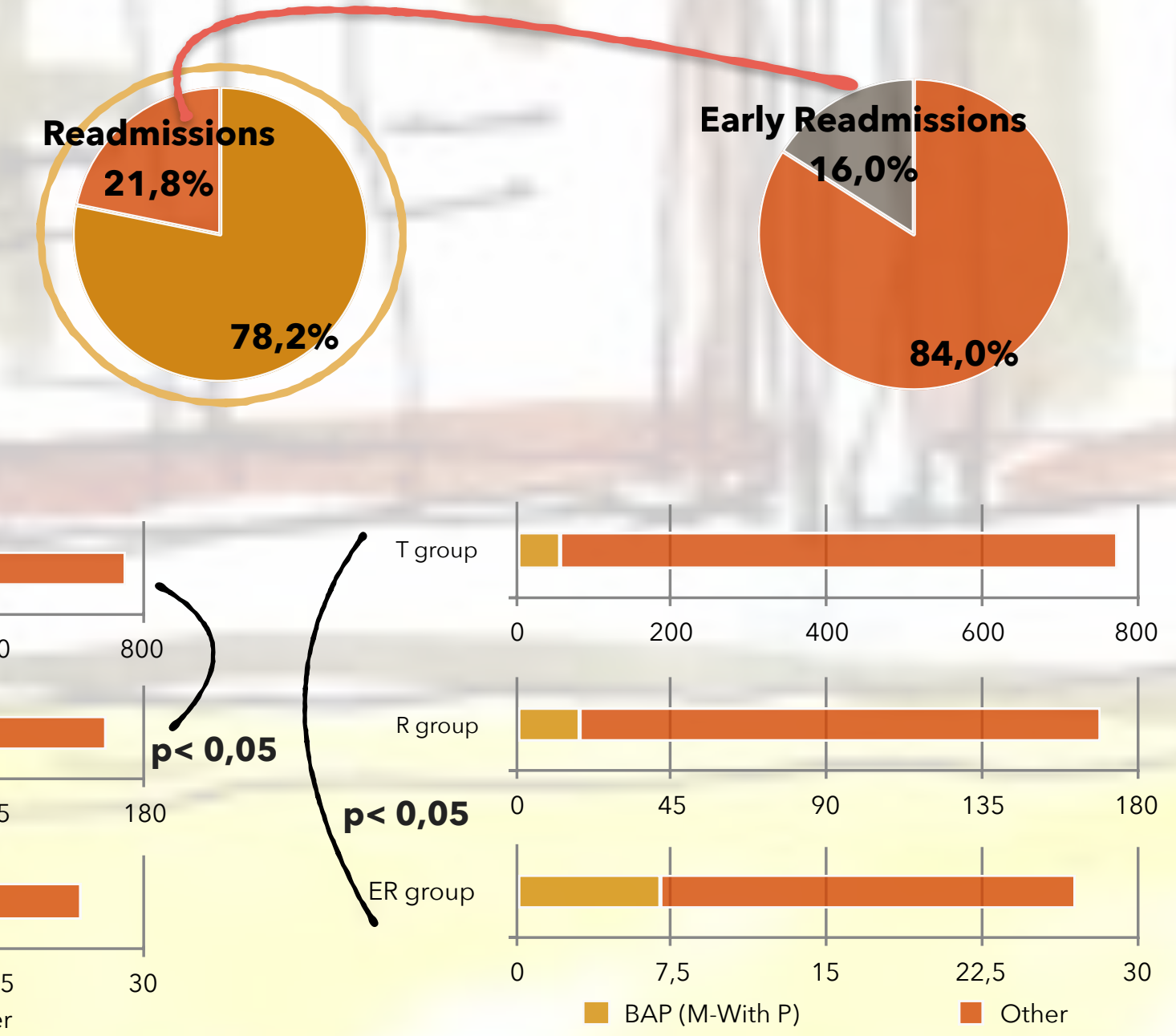

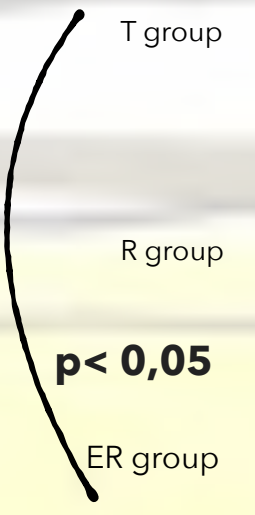

BAP (M-With P)
Other
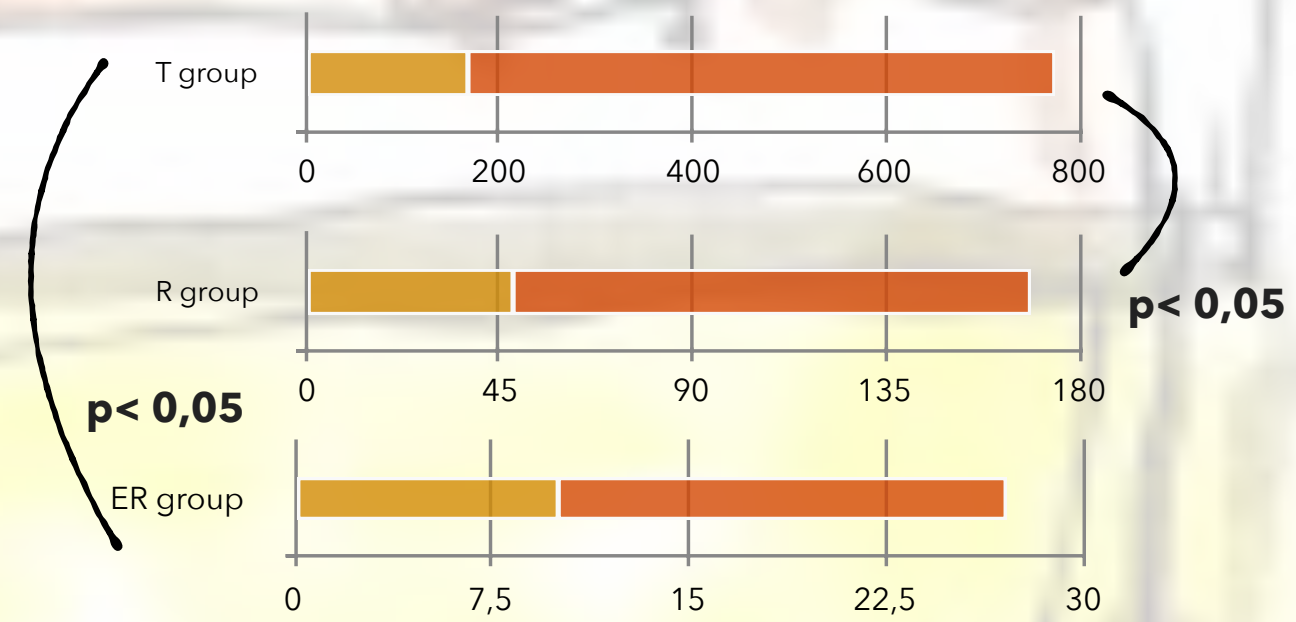

Unmarried

Othe

We compared R and ER groups with T group, and found:

$\checkmark$ Diagnosis of PS: significantly more frequent in $R$ and ER group compared with $T$ group;

$\checkmark$ Diagnosis of BAP (M-with P): significant hight frequency only in the ER group but not in $R$ group;

$\checkmark$ Use of depot medication: unremarkable. It seemed not to prevent readmissions in this population;

$\checkmark$ Characteristics of male gender and unemployed/retired status: significantly frequent in the $R$ group but not in the ER group.

However, the unmarried status was significant both in $R$ and ER groups.

To sum up, in this sample of inpatients, the features associated to readmissions during the first $\mathbf{3 0}$ days after discharge were: diagnosis of PS, diagnosis of BAP (M-with P) and unmarried status. The others sociodemographic characteristics studied did not had a relevant role on the ER phenomena; neither the use of a depot medication. This is contrary to what is described in the literature.

With these results, we could suggest a stricter outpatient monitoring for patients with PS and BAP (M with P) diagnoses and subjects with unmarried status, in order to prevent their early readmissions. However, this work had some limitations, as the population dimension or the inclusion and exclusion criteria.

We concluded a deeper knowledge of factors related to early readmissions may not only improve patient prognosis, but also reduce recovery times and cost of care. 